\title{
North Carolina reflects on ammonia controls
}

\section{Jessa Netting, Washington}

State legislators and environmental officials around the United States are watching their colleagues in North Carolina closely to see what action they take to control ammonia emissions - currently unregulated - from the state's animal production facilities.

Next week, members of a scientific committee, assembled by state agencies in North Carolina to investigate ways of processing and storing the waste, will meet to decide whether to recommend immediate regulation to meet concerns that the emissions are a potential health and environmental hazard.

Some members of the committee including its chair, Wayne Robarge, a soil physical chemist at North Carolina State University - argue that more scientific and technical assessments are needed to ensure that its recommendations are well informed.

Pai Yei Whung of the National Oceanic and Atmospheric Administration also says that more study is necessary. But she points out that, as there is currently no federal rule regulating ammonia concentrations at levels that are not immediately hazardous to health, the large animal production industry can claim "that they aren't violating any laws".

Gaseous ammonia is washed out of the

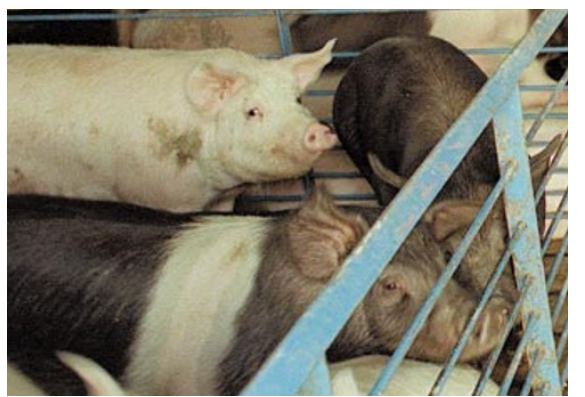

In the dock: pig production has been blamed for rising ammonia levels - but are they a hazard?

atmosphere when it rains, and enters streams, rivers and estuaries in North Carolina, where it increases the amount of nitrogen in the system. If it is converted while airborne to ammonium nitrate, it could make its way even further afield, to the estuaries and bays along the Maryland coast.

The Environmental Protection Agency has recently targeted ammonium nitrate for regulation under Clean Air Act standards on the grounds that it is a danger to human health. And gaseous ammonia may account for up to half of the nitrogen levels in some waterways along the Atlantic coast, Robarge and other chemists told a meeting of the
American Chemical Society in Washington last week.

But scientific uncertainty surrounds the relationship between how much gaseous ammonia emitted will rain into bodies of water, and how far ammonia and its products can be transported by the wind. This has prompted Robarge to oppose regulation until the impacts and influence are clear and the alternative technologies have been sorted out.

From a purely air-quality perspective, Whung describes levels of ammonia immediately surrounding swine-production operations as "disturbing". She has monitored ammonia in North Carolina with Robarge, and is now concerned with atmospheric ammonia deposition in Chesapeake Bay, Maryland, which is within North Carolina's 'air shed'.

At last week's American Chemical Society meeting, evidence was presented that cars, rather than livestock, may be the main source of ammonia in the atmosphere. In a study of 4,500 vehicles, researchers from the Oak Crest Institute of Science in California found ammonia levels from car exhausts were so high that they estimated cars are adding twice as much ammonia to the air of the state's southern coastal basin as livestock. 